\title{
Youth mental health in Ireland: a lot done, more to do?
}

\author{
H. Coughlan ${ }^{1 *}$ and M. Doyle ${ }^{2,3}$ \\ ${ }^{1}$ Department of Psychiatry, Royal College of Surgeons in Ireland, Dublin, Ireland \\ ${ }^{2}$ Child and Adolescent Mental Health Services, Health Service Executive, Monaghan, Ireland \\ ${ }^{3}$ Chair of Faculty of Child and Adolescent Psychiatry, College of Psychiatrists in Ireland, Dublin, Ireland
}

\begin{abstract}
The emergence of a new youth mental health paradigm has challenged how we think about the provision of mental health care for adolescents and young adults. This editorial tracks the origins of this new paradigm within the field of mental health both internationally and in Ireland.
\end{abstract}

Received 15 October 2014; Revised 5 November 2014; Accepted 14 November 2014

Key words: Adult mental health, child and adolescent mental health, mental health services, youth mental health.

The assimilation of the term youth mental health into the lexicon of psychiatry, both in Ireland and internationally, is an indication that a new paradigm is evolving. Using empirical evidence on mental ill-health during the developmental period from adolescence to young adulthood, this new youth mental health paradigm is challenging long-standing beliefs about how we think about young people's mental health. It is also challenging the way in which mental health care is currently organised and structured.

The emergence of the youth mental health paradigm is linked to a growing body of epidemiological evidence that has highlighted high rates of mental ill-health among young people during their adolescent and early adult years. Globally, the adolescent and early adult years have been identified as the peak period for the onset of mental ill-health (Jones, 2013) and it is estimated that one in five young people is experiencing a diagnosable mental disorder at any given time (Costello et al. 2011). Similar rates of disorder have been found among young people in Ireland: two recent Irish studies found a lifetime prevalence for any Axis I DSM-IV disorder of $31.2 \%{ }^{1}$ among $11-13$ year olds (Coughlan et al. 2014) and of 56\% among 19-24 year olds (Cannon et al. 2013). Paradoxically, in spite of evidence that the onset of mental ill-health peaks during youth, it is during this very developmental period that mental health services have been at their weakest (McGorry, 2007). This has resulted in significant numbers of young people being

* Address for correspondence: H. Coughlan, Department of Psychiatry, RCSI, RCSI Education \& Research Centre, Beaumont Hospital, Dublin 9, Ireland.

(Email: helencoughlan@rcsi.ie)

${ }^{1}$ Rate excludes specific phobia. Reported lifetime prevalence rate including specific phobia was $36.8 \%$. excluded from or unable to access mental health services at the very time that they need them most. For example, the use of the arguably arbitrary measure of age as a criterion for inclusion in or exclusion from mental health services has resulted in many young people in the 16-18 year age range potentially being excluded from both child and adolescent and from adult mental health services solely on account of their age. The youth mental health paradigm challenges this kind of approach to service delivery, arguing that services should be informed by available epidemiological evidence and organised on the basis of need, rather than on historically embedded service structures that date back as far back as the 17 th century.

Along with evidence of high rates of disorder among young people in the 12-25 year age range, it has also been recognised that it is young people who are carrying the burden of mental ill-health across the globe (Collishaw et al. 2004; Eckersley, 2011). The World Health Organisation figures on the global burden of disease demonstrate that neuropsychiatric disorders are the leading cause of disability for young people aged 10-24 years, accounting for $45 \%$ of years lost to disability (Gore et al. 2011). The finding that $75 \%$ of adults with a mental disorder will have had an onset of that disorder by the age of 25 years (Kessler et al. 2005; Jones, 2013) also suggests high rates of continuity in psychopathology over time. This places young people at high risk of developing enduring and potentially intractable mental health difficulties, with the additional risks of social and vocational exclusion, stigma and discrimination, restricted access to health and social services and higher rates of disability and premature death (Funk et al. 2010). Such evidence raises significant concerns about the impact of mental ill-health, not only on young people themselves, but 
also on their families, communities and wider society over time (Insel, 2008) and strengthens the argument that youth is a critical period to focus efforts at early detection and intervention.

The case for a new youth mental health paradigm is further strengthened by new theories of human development. A critical concept that has arisen from research findings is that of emerging adulthood (Arnett, $2000,2007)$. It suggests that, for young people in the developed world, the transition from adolescence to adulthood takes place over an extended period of time from the early- to mid-teens until the mid- to late-20s. The level of biological, psychological and social developmental heterogeneity that characterises this phase of the lifespan has been identified as a key aspect of emerging adulthood. Youth mental health advocates have argued that services should reflect this extended developmental phase of life and be structured in a way that ensures continuity of care across the adolescent and early adult years.

Finally, the emergence of the youth mental health paradigm has been influenced by young people themselves who have spoken up and spoken out about their experiences of mental ill-health and of mental health services. They have argued that traditional service structures and models of care can be unsuited to their needs (Garcia et al. 2007). Their voices have been supported by evidence of high rates of sub-optimal transitions and dissatisfaction among young people who require a transfer of care from child and adolescent to adult mental health services (Singh et al. 2010; McNamara et al. 2014).

In Ireland, youth mental health developments first emerged $\sim 8$ years ago when new philanthropic funding for youth mental health initiatives became available to Irish organisations. These philanthropic funding streams, in particular those from the One Foundation, supported the establishment of new dedicated youth mental health organisations like Headstrong, the National Centre for Youth Mental Health and ReachOut.com, Ireland's first dedicated youth mental health website.

The subsequent piloting of Headstrong's Jigsaw initiative demonstrated that new and creative services could be successfully developed, offering an alternative to traditional mental health services in Ireland that follow a paediatric-adult service split. Critically, these developments were also influenced by leading global youth mental health advocate, Professor Patrick McGorry. During a sabbatical he took in Ireland, in 2008 and in subsequent years, Professor McGorry has worked with youth mental health advocates, organisations and government representatives in Ireland to support efforts to progress enhanced mental health service provision for Irish youth.

At the same time that developments were emerging within the NGO sector in Ireland, a new National Special
Interest Group in Youth Mental Health was established, which provided a forum for a range of multi-disciplinary professionals to share knowledge and research on youth mental health (http://www.acamh.org/sig/ early-intervention-youth-mental-health-sig). Uniquely, the group included psychiatrists from both child and adolescent and adult mental health services. In 2010, the group hosted an International Summit in Youth Mental Health in Ireland, which brought together over 80 leading international researchers and professionals, young people and family members to discuss the future of youth mental health. At the Summit it was agreed that a new Declaration was necessary to support youth mental health service developments internationally. Significantly, Ireland took the lead in developing, writing and launching the International Declaration in Youth Mental Health, which was published in 2012 (www.iaymh.org/f.ashx/8909_Int-Declaration-YMH_ print.pdf). The Declaration sets out a consensus statement and a set of targets for the provision of specialist mental health services for 12-25 year olds across the globe (Coughlan et al. 2013).

Most recently, the College of Psychiatrists in Ireland adopted Youth Mental Health as their annual theme for 2013 (www.irishpsychiatry.ie/Ext-Affairs-Policy/CollegeTheme2013YouthMentalHealth.aspx). Given that specialist mental health services have continued to adopt a traditional child-adult split in their approach to service delivery and given the reality of service demands and budget restrictions in both child and adolescent and adult services across Ireland, the adoption of this theme by the College of Psychiatrists was considered to be a significant and positive development in national efforts to engage with the youth mental health paradigm. The adoption of the theme by the College of Psychiatrists offered a unique opportunity to engage members of both the child and adolescent and the adult faculties by raising awareness of the youth mental health paradigm, by providing members with the latest epidemiological evidence concerning Irish and international youth and, most importantly, by encouraging dialogue and engagement with the issue across the College of Psychiatrists. In addition, through the adoption of the theme, relationships between the College of Psychiatrists and other youth mental health agencies and practitioners and with young people themselves were fostered and nurtured to make the theme a success. This was done by establishing a core group with membership from the child and adolescent and adult faculties of the College of Psychiatrists, representatives from the National Special Interest Group on Youth Mental Health, and representation from youth mental health organisations such as ReachOut.com. The range of activities supported by the College of Psychiatrists included the writing of a 


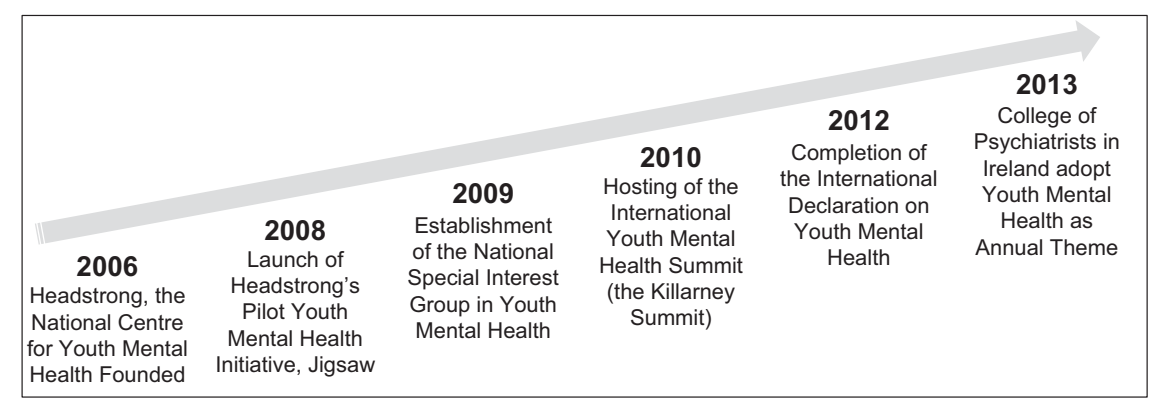

Fig. 1. The evolution of youth mental health in Ireland, 2006-2013.

paper to launch the theme, two presentations at the annual general meeting of the College of Psychiatrists, inclusion of a state-of-the-art youth mental health lecture at the European Society for Child and Adolescent Psychiatry Congress, hosted by the College of Psychiatrists in Dublin, running public talks and developing a College of Psychiatrists position paper on the theme. In addition, the theme was incorporated into the annual Spike Milligan debating competition run by the College of Psychiatrists for medical students across Ireland. The College of Psychiatrists also funded a prize for a youth mental health film competition run by ReachOut.com (http://ie.reachout.com/inspire-ageneration-film-awards-2013/) (Fig. 1).

Notwithstanding the progress Ireland has made to date, ensuring adequate resourcing to create quality and responsive services for young people remains a significant challenge in Ireland. If we embrace this challenge, we have the opportunity to transform the kind of mental health care we provide to our young people and, in so doing, to potentially alter the trajectories of young people's lives long into the future. With a shared strategic vision and a collective effort, we have the opportunity to provide appropriate, accessible, high quality mental health services to young people across Ireland and to leave a new legacy of mental health services for generations to come.

\section{Acknowledgements}

Helen Coughlan is currently employed under a Health Research Board Interdisciplinary Enhancement Capacity Award in Youth Mental Health (HRB/ICE/2012/11).

\section{References}

Arnett JJ (2000). Emerging adulthood. A theory of development from the late teens through the twenties. American Psychologist 55, 469-480.

Arnett JJ (2007). Emerging adulthood: what is it, and what is it good for? Child Development Perspectives 1, 68-73.

Cannon M, Coughlan H, Clarke M, Harley M, Kelleher I (2013). The Mental Health of Young People in Ireland: a report of the Psychiatric Epidemiology Research across the Lifespan (PERL) Group. Royal College of Surgeons (RCSI): Ireland, 44pp.
Collishaw S, Maughan B, Goodman R, Pickles A (2004). Time trends in adolescent mental health. Journal of Child Psychology \& Psychiatry \& Allied Disciplines 45, 1350-1362.

Costello EJ, Copeland W, Angold A (2011). Trends in psychopathology across the adolescent years: what changes when children become adolescents, and when adolescents become adults? Journal of Child Psychology \& Psychiatry E Allied Disciplines 52, 1015-1025.

Coughlan H, Cannon M, Shiers D, Power P, Barry C, Bates T, Birchwood M, Buckley S, Chambers D, Davidson S, Duffy M, Gavin B, Healy C, Healy C, Keeley H, Maher M, Tanti C, McGorry P (2013). Towards a new paradigm of care: the International Declaration on Youth Mental Health Early Intervention in Psychiatry 7, 103-108.

Coughlan H, Tiedt L, Clarke M, Kelleher I, Tabish J, Molloy C, Harley M, Cannon M (2014). Prevalence of DSM-IV mental disorders, deliberate self-harm and suicidal ideation in early adolescence: an Irish populationbased study. Journal of Adolescence 37, 1-9.

Eckersley R (2011). Troubled youth: an island of misery in an ocean of happiness, or the tip of an iceberg of suffering? Early Intervention in Psychiatry 5 (Suppl. 1): 6-11.

Funk M, Drew N, Freeman N, Faydi E (2010). Mental Health and Development: targeting people with mental health conditions as a vulnerable group. World Health Organisation: Geneva.

Garcia I, Vasilou C, Penketh K (2007). Listen Up: PersonCentred Approaches to Help Young People Experiencing Mental Health and Emotional Problems. Mental Health Foundation: London.

Gore FM, Bloem PJ, Patton GC, Ferguson J, Joseph V, Coffey C, Sawyer SM, Mathers CD (2011). Global burden of disease in young people aged 10-24 years: a systematic analysis. Lancet 377, 2093-2102.

Insel TR (2008). Assessing the economic costs of serious mental illness. American Journal of Psychiatry 165, 663-665.

Jones PB (2013). Adult mental health disorders and their age at onset. The British Journal of Psychiatry Supplement 54, s5-s10.

Kessler RC, Berglund P, Demler O, Jin R, Merikangas KR, Walters EE (2005). Lifetime prevalence and age-of-onset distributions of DSM-IV disorders in the National Comorbidity Survey Replication. Archives of General Psychiatry 62, 593-602.

McGorry PD (2007). The specialist youth mental health model: strengthening the weakest link in the public mental health system. Medical Journal of Australia 187, S53-S56. 
McNamara N, McNicholas F, Ford T, Paul M, Gavin B, Coyne I, Cullen W, O'Connor K, Ramperti N, Dooley B, Barry S, Singh SP (2014). Transition from child and adolescent to adult mental health services in the Republic of Ireland: an investigation of process and operational practice. Early Intervention in Psychiatry 8, 291-297.
Singh SP, Paul M, Ford T, Kramer T, Weaver T, McLaren S, Hovish K, Islam Z, Belling R,

White $\mathbf{S}$ (2010). Process, outcome and experience of transition from child to adult mental healthcare: multiperspective study. The British Journal of Psychiatry 197, 305-312. 